\section{Entopie - lokale Reaktion ohne Atopie?}

\author{
Allergische Erkrankungen müssen nicht zwangsläufig mit einer \\ Erhöhung des spezifischen IgE im Serum einhergehen. So zeigen \\ beispielsweise manche nicht atopische Patienten mit einer \\ idiopathischen Rhinitis eine IgE-vermittelte allergische Reaktion \\ der Nasenschleimhaut.
}

in internationales Forscherteam ver-
glich die nasale Mukosa von zehn
nicht atopischen und elf atopischen Pa-
tienten mit einer persistierenden Rhini-
tis mit der von zwölf gesunden Kon-
trollpersonen. Das Vorliegen einer Ato-
pie wurde durch Pricktest sowie durch
Messung von spezifischem und Ge-
samt-IgE verifiziert. Für den Nachweis
von spezifischen Allergen-bindenden
Antikörpern in der Nasenschleimhaut
wurden u. a. an einen Biotinkomplex
gebundene Allergene der Hausstaub-
milbe und von Gräserpollen verwendet.
Bei drei der zehn nicht atopischen
Rhinitiker wurde eine Gräserpollenall-
ergenbindung durch die Nasenschleim-
haut nachgewiesen, während die Tests

mit Hausstaubmilbenallergenen allesamt negativ ausfielen. Positiv verlief die Suche nach spezifischen Antikörpern bei acht der elf Mukosaproben der atopischen Patienten, negativ dagegen bei allen Kontrollpersonen. Die Allergenbindung bei nicht atopischen Patienten fand vor allem in unmittelbarer Nachbarschaft von Mastzellen statt.

Die Autoren kommen zu dem Schluss, dass entzündliche, offensichtlich durch Allergenbindung vermittelte Vorgänge in der Nasenschleimhaut auch ohne typische Befunde einer Atopie auftreten können. Für dieses Phänomen schlagen sie die Bezeichnung „Entopie“ vor, abgeleitet von dem griechischen Wort „entopos“, was lokal bzw. örtlich

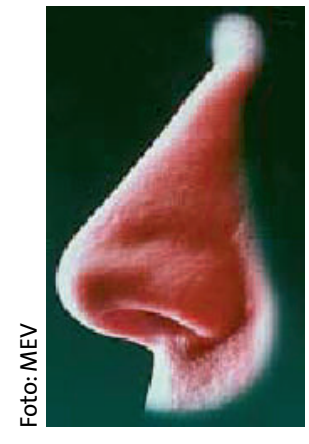

Die Nase vorn bei der Namensgebung für eine lokale nasale $\mathrm{Re}$ aktion ohne typische Atopiebefunde hatte das Team um D. G. Powe, Nottingham: „Entopie“ lautet sein Vorschlag.

ansässig bedeutet. Möglicherweise findet sich eine Entopie auch bei nicht atopischen Patienten mit anderen lokalen Reaktionen, z. B. an der Haut oder der Darmschleimhaut.

Fazit: Patienten mit einer idiopathischen Rhinitis können eine lokale, nasal begrenzte allergische Reaktion haben, ohne dass Pricktest oder spezifisches Serum-IgE positiv sind. $\quad b k$

Powe DG et al. "Entopy": localized mucosal allergic disease in the absence of systemic responses for atopy. Clin Exp Allergy 2003; 33: 1374-9

\title{
One skin - one airway - one disease?
}

\section{Die Expression von IgE-Rezeptoren (FcERI) auf der Oberfläche von Langerhanszellen ist ein zentraler Baustein in der Pathogenese der atopischen Dermatitis. Englische Immunologen wollten wissen, ob Fc $\in \mathrm{RI}$ auch bei anderen allergischen Erkrankungen eine Rolle spielt.}

$\mathrm{D}$ ie Langerhanszelle, Antigen-präsentierende dendritische Zelle der Epidermis, dient als immunologischer Wächter an der Grenze zwischen Körper und Umwelt. Über FceRI an die Zelloberfläche gebundenes Allergen-spezifisches IgE erleichtert die Antigen-Aufnahme und anschließende Präsentation. Ältere Studien zeigten die höchste FceRI-Oberflächenexpression in Hautläsionen von Patienten mit aktiver Neurodermitis. Dagegen exprimieren die Langerhanszellen nicht atopischer Menschen kaum FceRI.

Um der Rolle von FceRI auch bei anderen allergischen Erkrankungen auf die Spur zu kommen, verglichen Wis- senschaftler der Universität Southampton Epidermisproben aus der gesunden Haut von Patienten mit atopischer Dermatititis, mit Rhinitis bzw. mit Asthma mit Proben von NichtAtopikern. Die Proben wurden vor und nach Permeabilisation mit Anti-FceRIa und Anti-IgE inkubiert, um zwischen membraner und zytoplasmatischer Lokalisation zu unterscheiden.

Die FceRIa-Kette fand sich bei allen Probanden im Zytoplasma der Langerhanszellen. Membran-gebundene FceRI-IgE-Komplexe zeigten sich sowohl bei aktiver atopischer Dermatitis als auch bei allergischer Rhinitis und bei allergischem Asthma. Hingegen fehlte die Oberflächenexpression von FceRI bei Ekzempatienten in Remission sowie bei Nicht-Atopikern. Der IgE-Serumspiegel korrelierte nicht mit der Rezeptorexpression.

Offenbar regelt nicht ein gewebespezifischer, sondern ein systemischer Mechanismus die Expression der Fc $\in$ RI-Rezeptoren. Die Oberflächenexpression wäre daher Konsequenz und nicht Ursache einer allergischen Episode.

Fazit: Die FcєRI-Oberflächenexpression durch Langerhanszellen ist ein zeitlich begrenztes Phänomen und nicht spezifisch für die atopische Dermatitis, sondern generell mit atopischenen Erkrankung assoziiert.

Semper AE et al. Surface expression of FceRI on Langerhans' cells of clinically uninvolved skin is associated with disease activity in atopic dermatitis, allergic asthma, and rhinitis. J Allergy Clin Immunol 2003; 112: 411-9 